\title{
Asymmetry Analysis of Brontispa longissima Gestro, 1885 (Coleoptera: Chrysomelidae) Metasternum Using Symmetry and Asymmetry on Geometric Data (SAGE)
}

\author{
Debbie Gail P. Genotiva, Sharon Rose M. Tabugo, Muhmin Michael E. Manting, Jessie G. Gorospe, \\ Emma M. Sabado, and Cesar G. Demayo
}

\begin{abstract}
Variations in the patterns of asymmetry in coconut leaf beetle Brontispa longissima metasternum from ten (10) populations in Northern Mindanao, Philippines were evaluated using the landmark-based advanced geometric morphometrics Symmetry and Asymmetry in Geometric Data (SAGE) version 1.04 tool. Coconut leaf beetle has been infesting the country. However, primary information to the pest's ability to develop traits efficiently is still to be investigated. $B$. longissima metasternum was digitized and analyzed using Procrustes Analysis of Variance (ANOVA). Results have shown absence of fluctuating asymmetry between sexes and locations. Conversely, directional asymmetry and individual shape variation is evident for male and female samples in all sites.
\end{abstract}

Index Terms-Brontispa longissima, metasternum, procrustes ANOVA.

asymmetry,

\section{INTRODUCTION}

Thoracic segments play a crucial role in the life of the insects because these skeletons are modified to provide efficient support flight and locomotion. This is because the muscles of appendages and wings are attached to its intersegment folds [1]. In terms of insect flight mechanics, the power produced by muscles is transmitted to the wing via the complex interactions of hardened parts of the skeleton. Thus, all wing motion originates from the insect's thorax. Any deviation from its ideal structure either left or right might compromise the flight functions of the insect. To the researcher's best knowledge, this structure is less studied.

One way to study left and right variations in insect morphology is through asymmetry. Asymmetry is categorized in three forms, ie. fluctuating asymmetry (FA), antisymmetry (AS) and directional asymmetry (DA). Fluctuating asymmetry is defined as a pattern of variation between paired

Manuscript received March 4, 2014; revised May 12, 2014. This work was supported by the Department of Science and Technology under Accelerated Science and Technology Human Resource Development Program (DOST-ASTHRDP)

D. P. Genotiva is with the School of Graduate Studies - Mindanao State University at Iligan City 9200 Philippines (e-mail: debbiegenotiva@gmail.com).

S. R. M. Tabugo, M. M. E. Manting, and C. G. Demayo are with the Department of Biological Sciences in Mindanao State University - Iligan Institute Technology, Iligan, Philippines 9200 (e-mail: sharonrose0297@gmail.com,_muhminmichael.manting@gmail.com, cgdemayo@gmail.com).

J. M. Gorospe is with the School of Graduate Studies at the Naawan Campus of the Mindanao State University system.

E. M. Sabado is with the Plant Science Department, COA, MSU-Marawi, Marawi City, Philippines (e-mail: emcsab@yahoo.com). traits (e.g. left and right) where deviations from symmetry is normally distributed to a mean of zero, reflecting the stability of developmental processes. Palmer and Strobeck [2], [3] termed these deviations as 'developmental noise' which are environmentally or epigenetically induced stresses. Unlike the other types of (AS), fluctuating asymmetry (FA) have long been viewed as a measure of developmental instability [4] due to environmental stress [5]-[8], adaptation and coadaptation [9] and fitness or individual quality [10], [11]. There are several methods available in computing asymmetries. Traditionally, side variations were measured through mean and $\log$ differences of left and right metric traits with the aid of several statistical analyses. Rolf [12]-[14] has introduced an advanced method in quantifying asymmetry termed as Geometric Morphometrics. Being the crossroads of multiple fields of science: statistics, bioinformatics, geometry, ecology as well as evolutionary biology, Geometric Morphometrics has brought the traditional multivariate morphometrics into its new level as it has used landmark configurations for direct visualization in biological form, maintaining the shape aspect of a biological structure [13]. This powerful tool has been applied in asymmetry researches in vertebrates, arthropods and some insects but is not yet extended on other organisms. In this study, the investigation was focused on B. longissima (Gestro, 1885).

Coconut palm industry in the Philippines has faced a great challenge since the coconut leaf beetle pest $B$. longissima has invaded the country. This pest is believed to be endemic to Indonesia and Papua New Guinea and was not reported from the Southeast Asian countries until the late 1990's in Vietnam and locally last 2005 via shipment of ornamentals [15]. While chemical and biological controls have been conducted [16], [17], the damage due to infestation is still perceptible and has even reached to the southern islands of the country. In spite of being one of the most serious pests of coconut palm [18], the current knowledge about coconut leaf beetle is insufficient and its adaptability to different environments has not yet been investigated. Fundamental research is indispensable to fully understand the beetle and in turn develop applications for pest management. One way to measure the toughness of this species is through evaluating its ability to develop ideal bilateral parts despite the internal or external disruptions.

The aim of this study is to determine the type of asymmetry present among coconut leaf beetle species that thrive in Northern Mindanao Island using Geometric Morphometric tool, Symmetry and Asymmetry in Geometric Data (SAGE) v.1.04 [19]. Moreover, it seeks to compare if asymmetry differs from sexes and areas. It is hypothesized that $B$. 
longissima, being able to adapt and successfully thrive in areas with different ecological and climatic conditions, should be able to maintain a stabilized development in its structure. The thoracic segment used in this study is the metasternum where the dorsoventral flight muscle is attached. It is believed that this study will contribute fundamental knowledge in understanding the adaptability of coconut leaf beetle and would eventually aid to pest control.

\section{MATERIALS AND METHOD}

\section{A. Study Areas}

Male and female wild samples of coconut leaf beetle were collected from 10 areas in the northern part of Mindanao Island; Aloran, Misamis Occidental, Butuan City - Agusan del Norte, Dumalinao Zamboanga del Sur, Maramag Bukidnon, Pagadian City Zamboanga del Sur, Pantao Ragat Lanao del Norte, Parang Maguindanao, Sibutad Zamboanga del Norte, Trento Agusan del Sur and Wao Lanao del Sur. The said sampling locations are shown in Fig. 1.

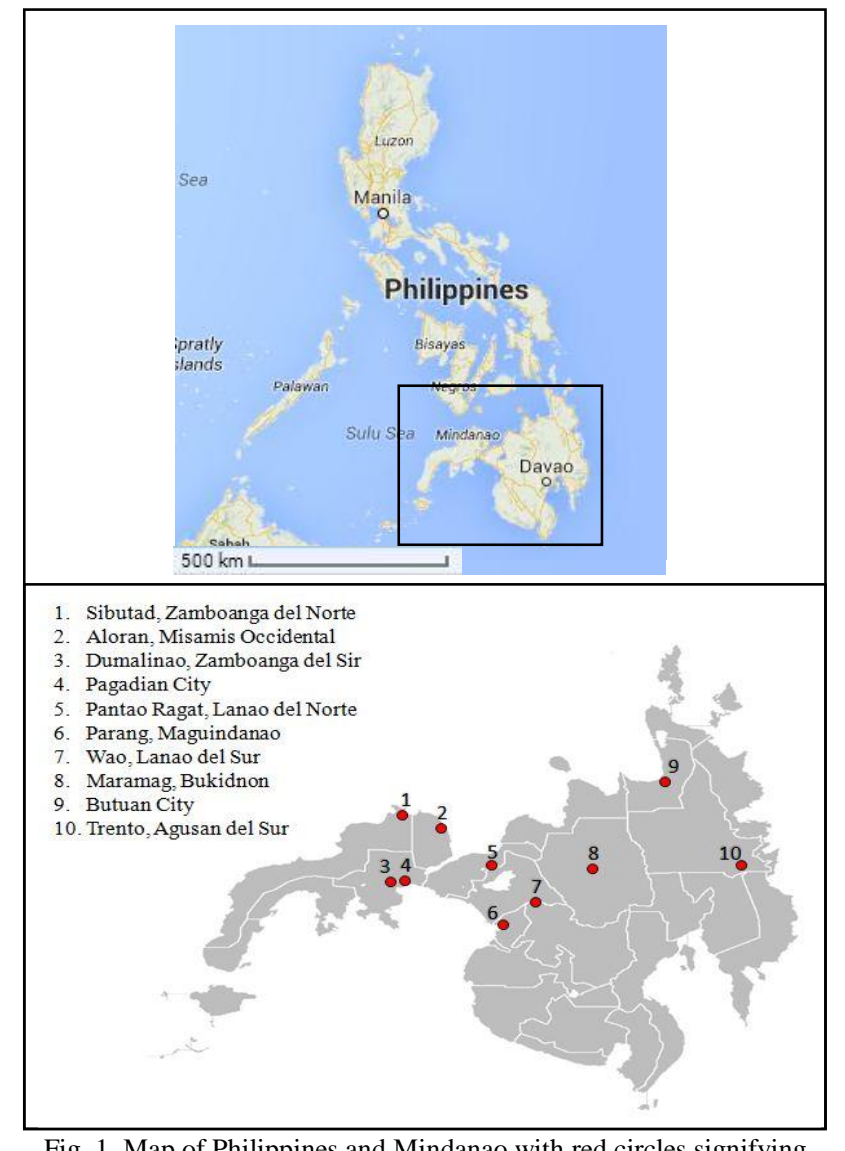

Fig. 1. Map of Philippines and Mindanao with red circles signifying the sampling locations.

\section{A. Sample Processing}

The collected individuals were placed in eppendorf tubes with $70 \%$ ethyl alcohol for preservation. Digital imaging of metasternum was done using a built in Digital SLR Camera (E-410, Zuiko Digital 14-42mm) on the Olympus SZ stereomicroscope. It was noted that the settings were kept constant i.e lighting, magnification (45x) and metasternum position. The captured images (ventral view) were digitized using TPS Utility Program (tpsUtil) [20] and saved as TPS file. After which, TPS version of the images was opened with TPS Dig v.2.12 (tpsDig2) [21] where landmark points and pseudolandmarks were plotted to obtain the 2D (" $x$ " and " $y$ ") coordinates of the corresponding morphological landmark points. The images were copied in triplicates to lessen inconsistencies or errors in plotting landmark points.

\section{B. Landmark and Protocol Selection}

Establishment of landmarks in this study was designated to the homologous and pronounced margins (e.g. sharp edges of the margin) found in metasternum. Pseudolandmarks were assigned to the points at extremes of curvature of the structure outline. A total of 31 landmark points were used to represent the whole shape of $B$. longissima metasternum as shown in Fig. 2. The landmark points with its corresponding descriptions were summarized in Table I. The analysis done was done specifically for object symmetry, symmetry axis passes through the centre of the structure [12]. Six (6) landmarks were defined as the lines of symmetry/ central axis. These were identified in the landmark pairing protocol (Saved as indivprot1.txt) with a zero. The homologous landmarks, corresponding to the same feature on the sides of the metasternums, were also paired off. On one hand, specimen identification protocol classifying the number of specimens in the dataset was labelled with the same ID for the replicates. The landmark configurations on one side were first reflected (Fig. 2-Right) followed with adjustments in scaling, rotation and orientation of metasternum employed through Procrustes Superimposition. The asymmetry of the entire object is computed as the difference between the original and the mirror configurations.

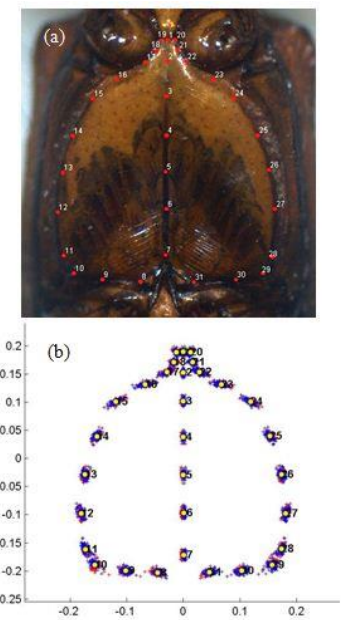

Fig. 2. (a) Assigned landmarks and pseudolandmarks on Brontispa longissina metasternum. (b) Procrustes fit of original (red) and reflected (blue) data. Light marks at the center of each point suggest bilaterally symmetrical points.

\section{Types of Asymmetry}

There are three recognized types of deviation from perfect symmetry: fluctuating asymmetry (FA), directional asymmetry (DA) and antisymmetry (AS). FA measure the pattern of variation of $L-R$ side difference wherein the variation is normally distributed to 0 mean, whereas in the case of DA, the variation is distributed normally but departs significantly from 0 (mean is $>$ or $<0$ ). This happens when one side of the trait is consistently larger than the other. Antisymmetry results from lack of symmetry in bilateral traits, distinguished by a bimodal 
and/or platykurtic (broad-peaked) distribution. This means that either left or right develop larger and are random. In this study, FA and DA were determined through Symmetry and Asymmetry in Geometric Data (SAGE) v.1.04 software whereas TPS dataset was tested for antisymmetry using PAST software Paleontological STatistics v 2.17b [22]. Tests for multivariate normality (Kurtosis $p<0.05$ ) and bimodal distribution (histogram) were done.

\section{TABLE I: CONTINUATION}

\begin{tabular}{|c|c|}
\hline LAND- & \\
\hline $\begin{array}{l}\text { MARK } \\
\text { NO. }\end{array}$ & DESCRIPTION \\
\hline 1 & $\begin{array}{l}\text { First LM on the apex of the central margin between LM } 19 \\
\& 20\end{array}$ \\
\hline 2 & $\begin{array}{l}\mathrm{LM} \text { in the central margin perpendicular to the point of } \\
\text { curvature on the left and right margins }\end{array}$ \\
\hline 3 & $\begin{array}{l}\text { LM in the central margin between LM2(above) and } \\
\text { LM4(below) }\end{array}$ \\
\hline 4 & $\begin{array}{l}\text { LM in the central margin between LM3(above) and } \\
\text { LM5(below) }\end{array}$ \\
\hline 5 & $\begin{array}{l}\text { LM in the central margin between LM4(above) and } \\
\text { LM6(below) }\end{array}$ \\
\hline 6 & $\begin{array}{l}\text { LM in the central margin at the border of the fiber-like } \\
\text { extensions between LM5(above) and LM7(below) }\end{array}$ \\
\hline 7 & $\begin{array}{l}\mathrm{LM} \text { above the } 2 \text { triangular body on the base of the central } \\
\text { margin }\end{array}$ \\
\hline 8 & $\begin{array}{l}\mathrm{LM} \text { in the left edge of the left triangular body of the basal } \\
\text { margin }\end{array}$ \\
\hline 9 & $\begin{array}{l}\mathrm{LM} \text { at the intersection point of the diagonal fiber-like } \\
\text { extensions and basal margin on the left metasternal plate }\end{array}$ \\
\hline 10 & $\begin{array}{l}\mathrm{LM} \text { at the intersection point of the diagonal fiber-like } \\
\text { extensions and lateral margin on the lowermost left } \\
\text { metasternal plate }\end{array}$ \\
\hline 11 & $\begin{array}{l}\mathrm{LM} \text { at the point of curvature of the left lateral margin } \\
\text { between LM10 and LM12 }\end{array}$ \\
\hline 12 & $\begin{array}{l}\mathrm{LM} \text { in the left border perpendicular to LM6 on the central } \\
\text { margin }\end{array}$ \\
\hline 13 & $\begin{array}{l}\mathrm{LM} \text { in the left border perpendicular to LM5 on the central } \\
\text { margin }\end{array}$ \\
\hline 14 & $\begin{array}{l}\mathrm{LM} \text { in the left border perpendicular to LM } 4 \text { on the central } \\
\text { margin }\end{array}$ \\
\hline 15 & $\begin{array}{l}\mathrm{LM} \text { in the left border perpendicular to LM3 on the central } \\
\text { margin }\end{array}$ \\
\hline 16 & $\begin{array}{l}\text { LM at the point of curvature of the upper left lateral margin } \\
\text { between LM15 and LM17 }\end{array}$ \\
\hline 17 & $\begin{array}{l}\mathrm{LM} \text { in the left border perpendicular to LM } 2 \text { on the central } \\
\text { margin }\end{array}$ \\
\hline 18 & $\begin{array}{l}\text { LM at the point of curvature of the upper left lateral margin } \\
\text { between LM17 and LM19 }\end{array}$ \\
\hline 19 & LM in the left edge of the apical horizontal axis \\
\hline 20 & LM in the right edge of the apical horizontal axis \\
\hline 21 & $\begin{array}{l}\mathrm{LM} \text { at the point of curvature of the upper right lateral } \\
\text { margin between LM } 20 \text { and LM } 22\end{array}$ \\
\hline 22 & $\begin{array}{l}\mathrm{LM} \text { in the right border perpendicular to LM } 2 \text { on the central } \\
\text { margin }\end{array}$ \\
\hline 23 & $\begin{array}{l}\text { LM at the point of curvature of the upper left lateral margin } \\
\text { between LM } 22 \text { and LM } 24\end{array}$ \\
\hline 24 & $\begin{array}{l}\mathrm{LM} \text { in the right border perpendicular to LM3 on the central } \\
\text { margin }\end{array}$ \\
\hline 25 & $\begin{array}{l}\mathrm{LM} \text { in the right border perpendicular to LM4 on the central } \\
\text { margin }\end{array}$ \\
\hline 26 & $\begin{array}{l}\mathrm{LM} \text { in the right border perpendicular to LM5 on the central } \\
\text { margin }\end{array}$ \\
\hline 27 & $\begin{array}{l}\mathrm{LM} \text { in the right border perpendicular to LM6 on the central } \\
\text { margin }\end{array}$ \\
\hline 28 & $\begin{array}{l}\text { LM at the point of curvature of the right lateral margin } \\
\text { between LM27 and LM29 }\end{array}$ \\
\hline 29 & $\begin{array}{l}\mathrm{LM} \text { at the intersection point of the diagonal fiber-like } \\
\text { extensions and lateral margin on the lowermost right } \\
\text { metasternal plate }\end{array}$ \\
\hline 30 & $\begin{array}{l}\mathrm{LM} \text { at the intersection point of the diagonal fiber-like } \\
\text { extensions and basal margin on the right metasternal plate }\end{array}$ \\
\hline 31 & $\begin{array}{l}\mathrm{LM} \text { in the right edge of the left triangular body of the basal } \\
\text { margin }\end{array}$ \\
\hline
\end{tabular}

\section{Landmark-Based Analysis and Statistical Analysis}

The TPS version of the landmarked images was subjected to Symmetry and Asymmetry in Geometric Data (SAGE) v.1.04 software to analyze the dataset with the SAGE manual as a reference [23]. Each of the aligned configurations which correspond to $\mathrm{x}$ - and $\mathrm{y}$-coordinates was used for further analysis. Procrustes two-way mixed model ANOVA with three replicates with 99 permutations was used to quantify the shape asymmetry of metasternum. The main effect is Sides which indicates the variation between sides and is the measure of directional asymmetry. While the block effect is individual, this is a measure of total random phenotypic variation. The individual by sides interaction is amixed effect, the failure of the individuals to be the same between sides (left and right). This measures the fluctuating asymmetry. Measurement error was also included. To further describe the variation PCA Principal Component Analysis (SAGE) was presented for visualization of the deformations and test for sex and location correlation.

\section{RESUlTS AND DISCUSSION}

Tests for antisymmetry have revealed that antisymmetry is absent in all of the $B$. longissima metasternum samples as indicated by non-significant $\mathrm{p}$ value of Kurtosis $(p>0.05)$ unimodal normal distribution. On another note, Procrustes ANOVA table lists the mean squares for the mixed-model ANOVA and its corresponding effects. Fisher's exact test (F-test) was used to determine the significance of null hypothesis of no difference between variance products $(X Y)$ in both left and right side. The "individuals" effect is the variation among individual samples and can be interpreted as shape/symmetry variation. The results measuring the directional asymmetry - DA $(p>0.05)$ is designated by the significant factor 'side' box in the SAGE main panel while fluctuating asymmetry (FA) is denoted by a significant $\mathrm{p}$ value $(P>0.05)$ of the interaction of 'side' and 'individual' (Individuals $\mathrm{x}$ sides). Procrustes ANOVA (Table II) shows that the asymmetry variations in male and female samples were due to DA and that no FA existed $(P<0.05)$. The observed deviations are not sex specific. Moreover, significant L-R size and shape variation is present, Individuals $p<0.05$.

TABLE II: PROCRUSTES ANOVA RESULTS IN B. LONGISSIMA SAMPLES IN TERMS OF SEX

\begin{tabular}{|c|c|c|c|c|}
\hline EFFECT & SS & dF & MS & $\mathbf{F}$ \\
\hline \multicolumn{5}{|l|}{ Female } \\
\hline Individuals & 1.968 & 7192 & 0.0003 & $7.202 *$ \\
\hline Sides & 0.037 & 29 & 0.0013 & $33.5856^{*}$ \\
\hline Individuals $x$ sides & 0.2733 & 7192 & 0 & 0.9431 \\
\hline \multicolumn{5}{|l|}{ Male } \\
\hline Individuals & 3.5056 & 7250 & 0.0005 & $14.8639 *$ \\
\hline Sides & 0.0438 & 29 & 0.0015 & $46.4207 *$ \\
\hline Individuals $x$ sides & 0.2358 & 7250 & 0 & 0.8801 \\
\hline Measurement error & 1.0762 & 29116 & 0 & -- \\
\hline
\end{tabular}

While all of the samples from Aloran, Misamis Occidental, Butuan City - Agusan del Norte, Dumalinao Zamboanga del 
Sur, Maramag Bukidnon, Pagadian City Zamboanga del Sur, Pantao Ragat Lanao del Norte, Parang Maguindanao, Sibutad Zamboanga del Norte, Trento Agusan del Sur and Wao Lanao del Sur (Table III) have shown a significant directional asymmetry based variation of left and right sides of metasternum $(P<0.05)$.

TABLE III: PROCRUSTES ANOVA RESULTS IN B. LONGISSIMA POPULATIONS

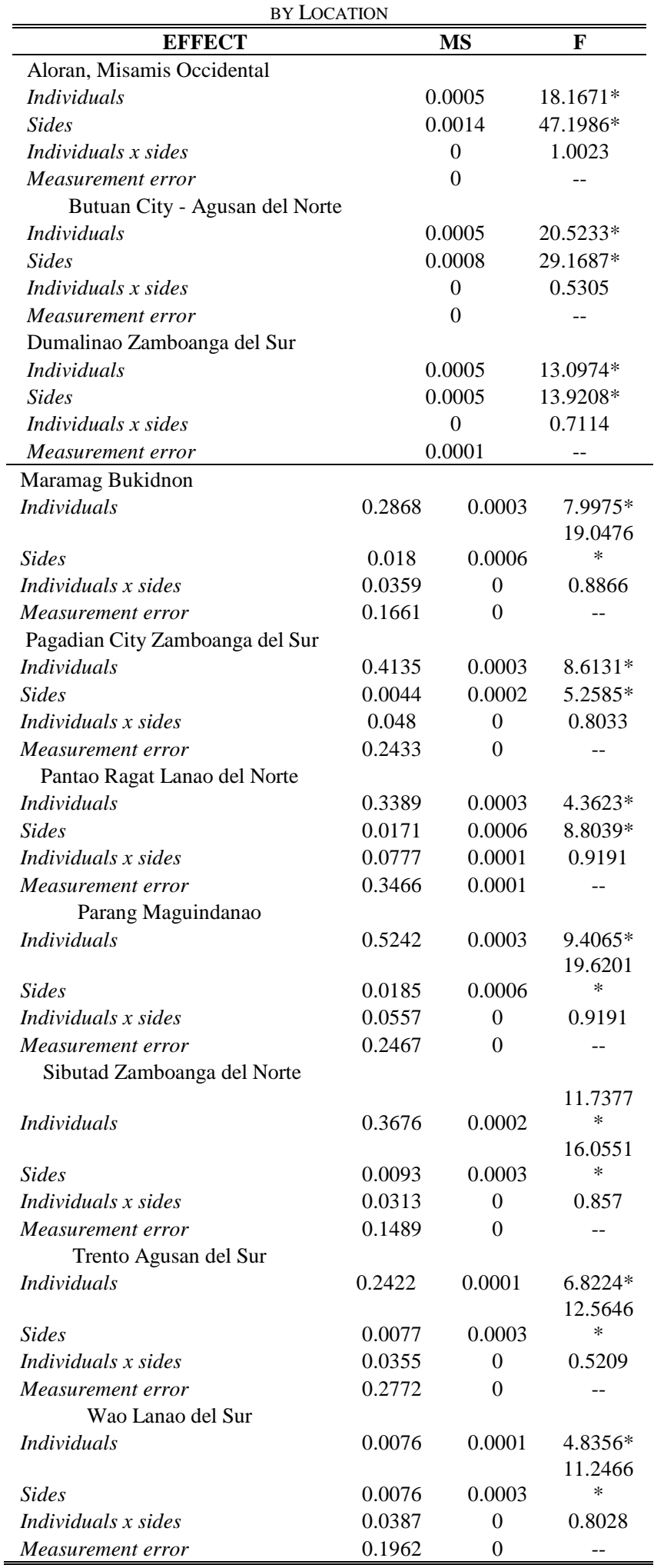

Note: side = directional asymmetry; individual $\mathrm{x}$ sides interaction $=$ fluctuating asymmetry; $* P<0.05$, statistically significant; significance was tested with 99 permutations.

Shown in Fig. 3 and Fig. 4 are the Principal component analyses of the covariance matrix associated with the symmetry component of variation. This was performed to further examine the visual individual variation of the left-right sides of the landmark configurations. Only two principal components were presented since they explain most of the variations. Axis 1 (PC1) on Fig. 3 explains about $40 \%$ and $50 \%$ of female and male samples, respectively. The variation is seen in the extreme curvatures of metasternum, specifically landmarks pairs 10, 11 and 28, 29 and 15-17 and 22-24. Although PC2 shows a slight difference (around 22\%) of variation between sexes, both PC1 and 2 exhibit similar deformations which are localized in lateral sides of metasternum. Directional asymmetry PCA was also done in male and female samples. Remarkably, a homogeneous deformation $(\mathrm{PC} 1=100 \%$ ) exhibited in both sexes favoring the right side of metasternum with slight downside movement of the right basal region (Fig. 4a).

Covariance matrix of directional asymmetry component of variation among different population groups shows a uniform $100 \%$ variation favoring the right side of metasternum. A minute downward movement of the right basal margin of the structure is detected as shown in Fig. 4a. However, Pantao Ragat group is an exemption (Fig. 4b) wherein erratic movement of most of the landmark points is displayed. A stretching of the right part of the structure can also be observed which explains the significant directional asymmetry L-R variation.

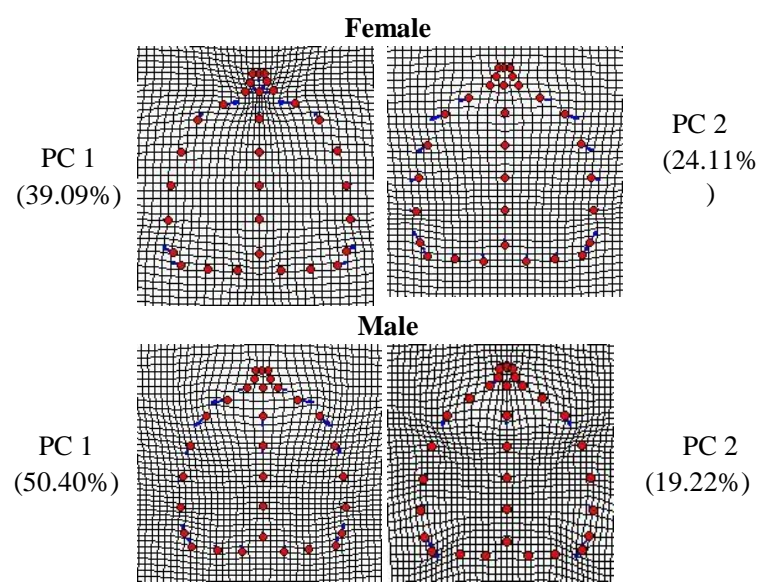

Fig. 3. PCA-implied deformation grid for individual variation (symmetric) in male and female B. longissima metasternum.

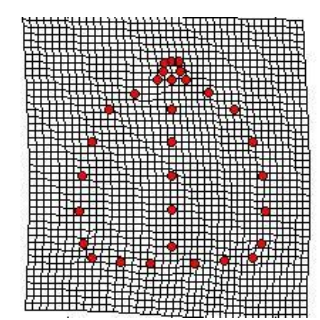

(a) PC1 $(100 \%)$

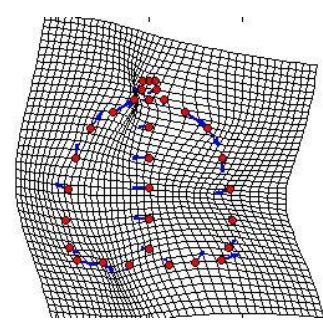

(b)PC1 $(100 \%)$
Fig. 4. PCA-implied deformation grid for side variation (directional asymmetry) of B. longissima metasternum a.) for both sexes and all locations except for b.) Pantao Ragat group.

Reflected in Fig. 5 are the individual shape variations for every sampling site. PC1 and 2 are only shown as they largely represent the total variation of the samples. Much variation occurs on the anterior part of metasternum starting from landmark pair 17 and 22 upwards. This model comprises $30-78 \%$ of the whole variation. Moreover, the said landmark 
pairs tend to move towards each other, resulting in narrower bridge towards the apex. The variation is a also attributed to the extreme curvature on the basal region of metasternum. Whereas in PC2, 5-38\% of the total variation among locations is explained by the same deformations in PC1 except for Pagadian and Pantao Ragat group. For Pagadian group, the landmarks on the lateral margins of the structure tend to move downward. A notable deformation can be observed in PC2 of Pantao Ragat population, with $19.41 \%$ percentage of the entire variation.

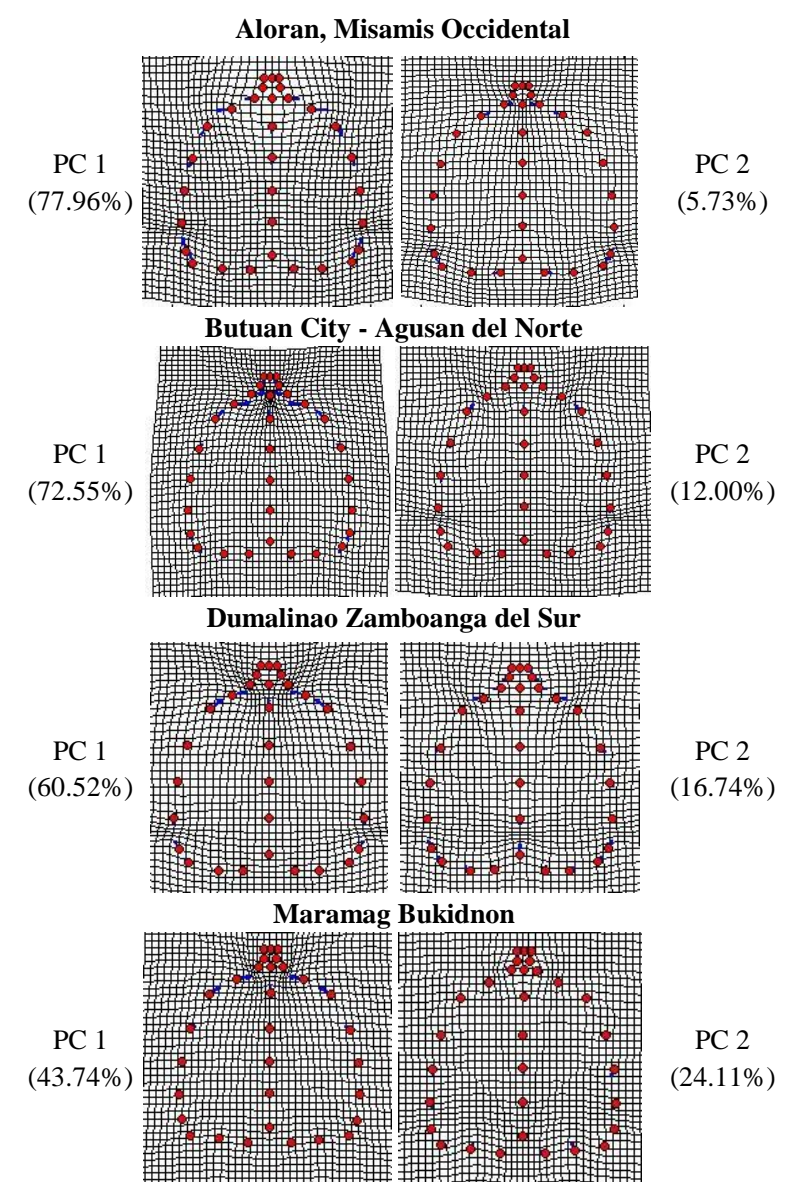

Fig. 5. PCA-implied deformation grid for individual variation (symmetric) of B. longissima metasternum in different locations.

Strong movement of landmark pair $13 \& 26$ towards the central axis is evident in this figure. While the anterior and posterior half of the structure tend to shift upwards and downwards, in that order.

This study has found a significant symmetric shape variation on metasternum among sexes and populations. This means that every change in shape on the left part of metasternum has a corresponding equal change on the right counterparts. The variation occurs in the entire shape of the structure among all samples although these differences are not sex and location specific (PAST PCA).

Based on the results shown, all of the sample male and female populations have undergone a significant directional asymmetry. This finding is similar to other studies of other structures particularly mouse skull [24] \& humerus [25] as well as wings of several insect species coming from different families [26], [27] but first recorded in insect metasternum. The reasons for the significant right side variation in metasternum morphology in this group of populations are still yet to be elucidated. However, as explained by Palmer and
Strobeck [28], for DA, a fraction of variation in L-R may have a genetic basis. This means that metasternum may have been developmentally or genetically directed to become asymmetrical. In this case DA is no longer a product of pure developmental noise. Several attempts to estimate genetic variation in DA have constantly failed [29], [30]. A small number of studies though, allowed DA to be employed in estimating developmental instability but in a limited way [31]. Directional asymmetry is widely common used among animals, particularly in internal organs [32]. In contrast, external asymmetries like DA are less prevalent but might be an adaptive form of asymmetry, corresponding to optimal fitness caused by a selective pressure [26]. Further research should be done to determine whether this argument holds true for B. longgissima metasternum.

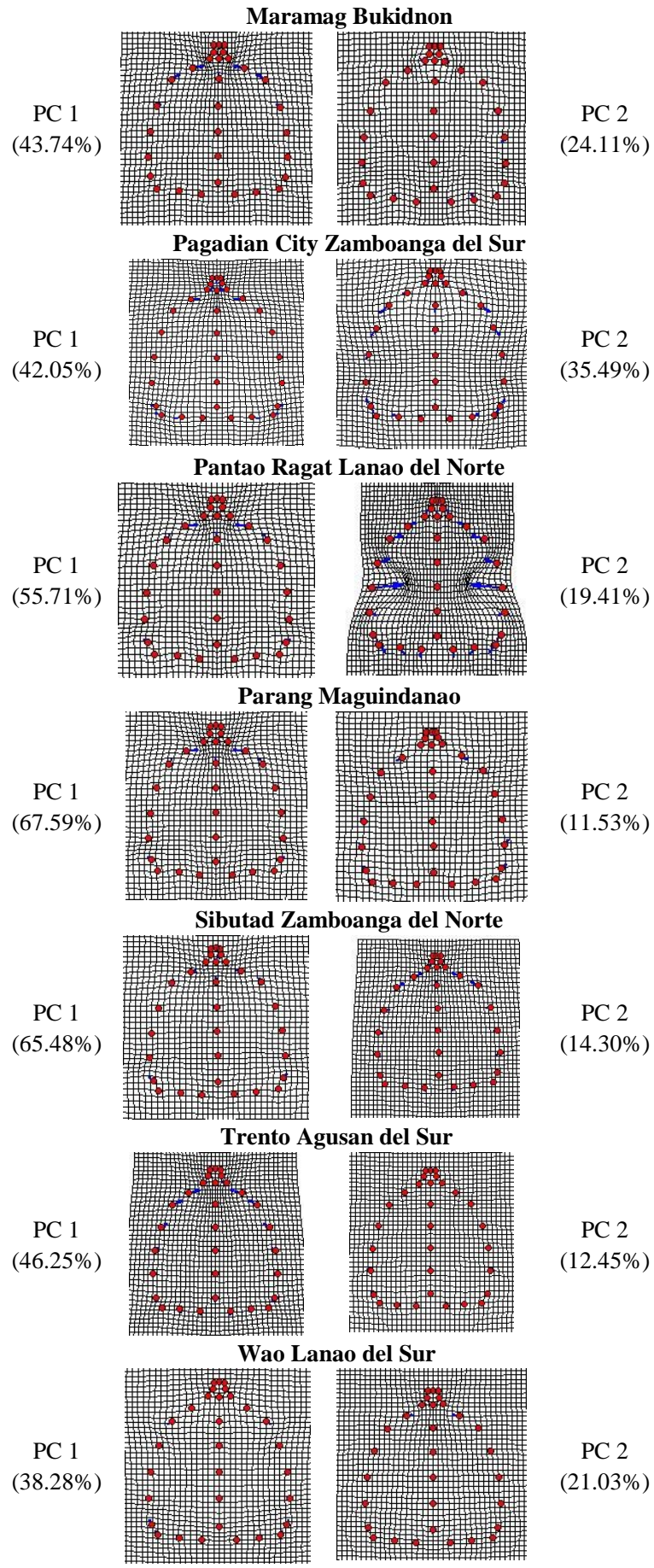

Fig. 6. Continuation. 


\section{CONCLUSION}

The results of this study show the utility of Symmetry and Asymmetry in Geometric Data (SAGE) landmark-based analysis in studying the patterns of variation in the metasternum of coconut leaf beetle B. longissima (Gestro, 1885) male and female populations in select locations of Northern Mindanao. It has been shown that fluctuating asymmetry is absent in all sample populations. However, all of the male and female samples coming from the 10 locations exhibit a significant directional asymmetry and individual (symmetric) variation. Future studies can be done to determine whether the side variation is genetically directed. It is also recommended that FA analyses be done to other bilateral traits of coconut leaf beetle to develop a more concrete perspective in the pest's adaptive mechanism.

\section{ACKNOWLEDGMENT}

The senior author would like to acknowledge the Philippine Department of Science and Technology under the Accelerated Science and Technology Human Resource Development Program for the scholarship and research funds.

\section{REFERENCES}

[1] R. F. Chapman, The Insects. Structure and Function, 5th ed., Cambridge: Cambridge University Press, 2013, ch. 7, pp. 150-156.

[2] A. R Palmer and C. Strobeck, "Fluctuating asymmetry as a measure of developmental stability: Implications of non-normal distributions and power of statistical tests," Acta Zoologica Fennica, vol. 191, pp. 57-72, 1992.

[3] A. R Palmer and C. Strobeck, Fluctuating Asymmetry Analyses Revisited. Developmental Instability: Causes and Consequences, Oxford University Press, Oxford, ch. 17, pp. 279-319, 2003.

[4] C. P. Klingenberg and H. F. Nijhout, "Genetics of fluctuating asymmetry: a developmental model of developmental instability,' Evolution, pp. 358-375, 1999.

[5] T. Eeva, S. Tanhuanpää, C. Råbergh, S. Airaksinen, M. Nikinmaa, and E. Lehikoinen, "Biomarkers and fluctuating asymmetry as indicators of pollution-induced stress in two hole-nesting passerines," Functional Ecology, vol. 14, no. 2, pp. 235-243, 2000.

[6] J. T. Manning and A. T. Chamberlain, "Fluctuating asymmetry in gorilla canines: a sensitive indicator of environmental stress," in Proc. the Royal Society of London. Series B: Biological Sciences, vol. 255, no. 1343 , pp. $189-193,1994$.

[7] V. Trotta, F. C. F. Calboli, F. Garoia, D. Grifoni, and S. Cavicchi, "Fluctuating asymmetry as a measure of ecological stress in Drosophila melanogaster (Diptera: Drosophilidae)," European journal of Entomology, vol. 102, no. 2, pp. 195-200, 2005.

[8] F. Söderman, S. van Dongen, S. Pakkasmaa, and J. Merilä, "Environmental stress increases skeletal fluctuating asymmetry in the moor frog Ranaarvalis," Oecologia, vol. 151, no. 4, pp. 593-604, 2007.

[9] J. H. Graham, S. Raz, H. Hel-Or, and E. Nevo, "Fluctuating asymmetry: methods, theory, and applications," Symmetry, vol 2, pp. 466-540, 2010.

[10] L. Lens, S. Dongen, S. Kark, and E. Matthysen, "Fluctuating asymmetry as an indicator of fitness: can we bridge the gap between studies?" Biological Reviews, vol. 77, no. 1, pp. 27-38, 2002.

[11] A. P. Møller and C. Zamora-Muñoz, "Antennal asymmetry and sexual selection in a cerambycid beetle," Animal behaviour, vol. 54, no. 6, pp. 1509-1515, 1997.

[12] F. R. James and L. F. Marcus, "A revolution morphometrics," Trends in Ecology \& Evolution, vol. 8, no. 4, pp. 129-132, 1997.

[13] D. C. Adams, F. J. Rohlf, and D. E. Slice, "Geometric morphometrics: ten years of progress following the 'revolution'," Italian Journal of Zoology, vol. 71, no. 1, pp. 5-16, 2004.

[14] P. Mitteroecker and P. Gunz, "Advances in geometric morphometrics," Evolutionary Biology, vol. 36, no. 2, pp. 235-247, 2009.

[15] S. K. Nakamura and K. Takasu, "Invasion of the coconut hispine beetle, Brontispa longissima: Current situation and control measures in Southeast Asia, International Workshop on Development of Database (APASD) for Biological Invasion, vol. 3, pp. 1-9, 2006.
[16] L. S. He, K. H. Ong, C. P. Yik, Y. K. Fong, and H. J. A. Chan, "Chemical control of hispid beetles (B. longissima) on palms," Singapore J PriInd, vol. 32, pp. 80-92, 2005.

[17] H. Vanhan, "Coconut beetle management in Cambodia. In Developing an Asian-Pacific Strategy for Forest Invasive Species: The Coconut Beetle Problem - Bridging Agriculture and Forestry," Asia-Pacific Forest Invasive Species Network Workshop, 22-25 February 2005, Rap Publication, 2007.

[18] Asia - Pacific Forest Invasive Species Network (APFISN), Coconut leaf beetle - Fact Sheet. [Online]. Available at http://www.fao.org/docrep/012/al350e/al350e00.pdf, 2008.

[19] E. Marquez. (2008). Sage: Symmetry and Asymmetry in Geometric DataVersion $\quad$ 1.05. [Online]. Available: http://www-personal.umich.edu/ emarquez/morph/

[20] F. J. Rohlf, TPS Utility Program Version 1.44, Dept. of Ecology \& Evolution, Stony Brook University, Stony Brook, NY 11794-5245, 2009.

[21] F. J. Rohlf, TPS Dig Version 2.12, Dept. of Ecology \& Evolution, Stony Brook University, Stony Brook, NY 11794-5245, 2009.

[22] O. Hammer, D. A. T. Harper, and P. D. Ryan, "PAST: Paleontological statictics software package for education and data analysis," Paleontologia Electronica, vol. 4, no. 1, p. 9, 2001.

E. Marquez, "Sage: Symmetry and Asymmetry in Geometric Data Version 1.04," Mammals Division University of Michigan Museum of Zoology, 2007.

[23] V. Debat, P. Alibert, P. David et al., "Independence between developmental stability and canalization in the skull of the house mouse," Royal Society of London. Series B: Biological Sciences, vol. 267, no. 1442, pp. 423-430, 2000.

[24] L. J. Leamy et al., "Size and fluctuating asymmetry of morphometric characters in mice: Their associations with inbreeding and T-Haplotype," Evolution, vol. 55, no. 11, pp. 2333-2341, 2001.

[25] C. Pelabon and T. F. Hansen "On the adaptive accuracy ofdirectional asymmetry in insect wing size,” Evolution, vol. 62, pp. 2855-2867, 2008.

[26] H. A. Benítez, D. Lemic, R. Bažok et al., "Evolutionary directional asymmetry and shape variation in Diabrotica virgifera virgifera (Coleoptera: Chrysomelidae): An example using hind wings,' Biological Journal of the Linnean Society, vol. 111, no. 1, pp. 110-118, 2014.

[27] A. R. Palmer and C. Strobeck, "Fluctuating asymmetry as a measure of developmental stability: Implications of non-normal distributions and power of statistical tests," Acta Zoologica Fennica, vol. 191, pp. 57-72, 1992.

[28] J. L. Monedero, D. Chavarrïas, and C. Löpez-Fanjul, "The lack of mutational variance for fluctuating and directional asymmetry in Drosophila melanogaster," Royal Society of London. Series B: Biological Sciences, vol. 264, no. 1379, pp. 233-237, 1997.

[29] R. C. Lewontin, "The problems of population genetics," Evolutionary Genetics: From Molecules to Morphology, Cambridge: Cambridge University Press, pp. 5-23, 2000.

[30] J. H. Graham, J. M. Emlen, and D. C. Freeman, "Nonlinear dynamics and developmental instability. Developmental instability: Causes and consequences," pp. 35-50, 2003.

[31] A. R. Palmer, "Symmetry breaking and the evolution of development," Science, vol. 306, no. 5697, pp. 828-833, 2004.

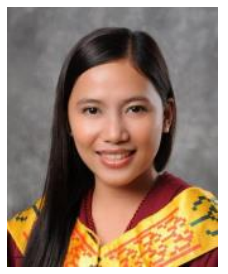

Debbie Gail P. Genotiva is currently a student of masters in biology under the School of Graduate Studies - Mindanao State University at Iligan City 9200 Philippines. She is a grantee of Department of Science and Technology - Accelerated Science and Technology Human Resource Development Program (dost-asthrdp) scholarship. She finished her undergraduate degree, bachelor of science in biology General Biology in the

same institution last April 2012

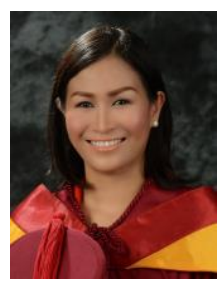

Sharon Rose M. Tabugo is an associate professor in the Department of Biological Sciences in Mindanao State University - Iligan Institute Technology. 


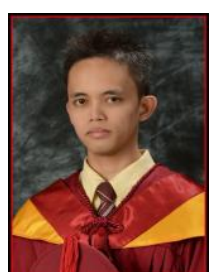

Muhmin Michael E. Manting is an instructor in the Department of Biological Sciences in Mindanao State University - Iligan Institute Technology.

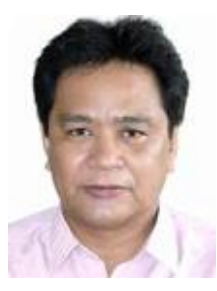

Jessie G. Gorospe is a faculty and the dean of the School of Graduate Studies at the Naawan campus of the Mindanao State University system.

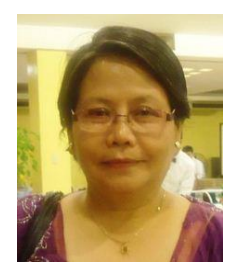

Emma M. Sabado is a facutly in the College of Agriculture, Mindanao State University Main Campus, Marawi City, Philippines. She is in charge of the Butterfly Garden \& Strawberry Production Project.

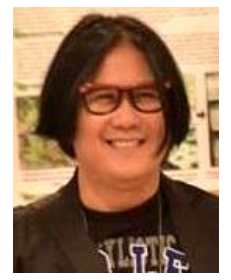

Cesar G. Demayo is a biology professor and the current chairperson of the Department of Biological Sciences, College of Science and Mathematics, MSU-Iligan Institute of Technology, Iligan City, Philippines. His researches include environmental toxicology, biodiversity and genetics. He is an active member of the Philippine Society for the Study of Philippines. 